УДК 549.67, 544.726

DOI https://doi.org/10.15673/swonaft.v84i1.1878

\title{
ДОСЛІДЖЕННЯ ТЕРМОДИНАМІКИ АДСОРБЦІї ОРТОФОСФОРНОЇ КИСЛОТИ ПРИРОДНИМ ЦЕОЛІТОМ У СТАТИЧНИХ УМОВАХ
}

\author{
Сабадаш В.В., д-р техн. наук, доцент \\ Гумницький Я.М., д-р техн. наук, професор \\ Національний університет «Львівська політехніка», м. Львів
}

\begin{abstract}
Анотація. В роботі приведено результати досліджень термодинаміки процесу адсорбиії фосфатів 3 модельного розчину ортофосфорної кислоти в статичних умовах. Досліджено зміну рН розчинів фосфатів y процесі адсорбиії. Адсорбиію фосфатів було описано ізотермами Фрейндліха та Ленгмюра iз $R^{2}>0.9$. Встановлено, щз ізотерму адсорбиії ортофосфорної кислоти можна описати ізотермою БЕТ (Брунауера, Еммета $і$ Теллера). Параметри рівняння БЕТ для процесу адсорбиії фосфату цеолітом наступні: $1 /($ amK $)=0.0196 ;\left(K^{-1}\right) /\left(a_{m} K\right)=0.3304 ; K=0.99352416$; максимальне значення адсорбиійної здатності на фосфатах у полімолекулярному шарі $a_{m}=51,35296$. Термогравіметричним методом досліджено иеоліт до та після адсорбиії фосфатів. В роботі представлено дериватограми досліджуваних зразків природного цеоліту та зразка після адсорбиії ортофосфорної кислоти з 10\% розчину. Нами проведено розрахунки термодинамічних параметрів реакцій які можливі під час адсорбиії фосфатів з концентрованих розчинів ортофосфорної кислоти природним цеолітом. Постановка питання полягала у встановленні імовірності утворення поліфосфату, який було ідентифіковано за значенням температури фазового переходу на термограмі як натрію трифосфат. Приведено реакиії взаємодії фосфатів з поверхнаю иеоліту. Приведено розрахунки термодинамічних параметрів для різних варіантів проходження реакиій взаємодї фосфатів 3 цеолітовою матрицею. Встановлено найбільш імовірну схему взаємодії згідно значень ізобарноізотермічного потенціалу. Розраховано термодинамічні параметри даних реакиій. Встановлено, щзо хемосорбиія фосфатіону та утворення полі фосфату в порах сорбенту є спонтанною реакиією. Для даної реакції за температури $t=298{ }^{\circ} \mathrm{K}$ ізобарно-ізотермічний потенціал становив $\Delta G=-1202.91$, кДж / моль, зміна ентропії $\Delta S^{\circ}{ }_{298}=0.397 \kappa Д ж$ / (моль K), зміна ентальпї $\Delta H^{\circ}{ }_{298}=-1084.6 \kappa Д ж$ / моль.
\end{abstract}

Ключові слова: стічні води, фосфати, цеоліт, термодинаміка, термогравіметрія

\section{INVESTIGATION OF THERMODYNAMICS OF ORTHOPHOSPHORIC ACID ADSORPTION BY NATURAL ZEOLITE UNDER STATIC CONDITIONS}

\author{
Sabadash V. V. Doctor of Technical Sciences, Associate Professor \\ Gumnitsky J. M. Doctor of Technical Sciences, Professor \\ Lviv National Polytechnic University, Lviv, Ukraine
}

\begin{abstract}
The article presents the main outcomes on the thermodynamics of the phosphate adsorption process from a model solution of orthophosphoric acid under static conditions. The pH change of phosphate solutions during adsorption has been studied. Phosphate adsorption was described by Freundlich and Langmuir isotherms with $R^{2}>0.9$. It is established that the orthophosphoric acid adsorption isotherm can be described by the BET (Brunauer, Emmett and Teller) isotherm. The parameters of the BET equation for the process of phosphate adsorption by zeolite are as follows: $1 /\left(a_{m} K\right)=0.0196 ;\left(K^{-1}\right) /\left(a_{m} K\right)=0.3304 ; K=0.99352416$; the maximum value of the adsorption capacity on phosphates in the polymolecular layer $a_{m}=51,35296$. The zeolite before and after phosphate adsorption was investigated by thermogravimetric method. The paper presents derivatograms of the studied samples of natural zeolite and the sample after adsorption of orthophosphoric acid from 10\% solution. We have calculated the thermodynamic parameters of reactions that were possible during the adsorption of phosphates from concentrated solutions of orthophosphoric acid by natural zeolite. The question was to determine the probability of formation of polyphosphate, which was identified by the value of the phase transition temperature on the thermogram as sodium triphosphate. The reactions of phosphate interaction with the zeolite surface were given.
\end{abstract}

Наукові праці, Том 84, випуск 1 Scientific Works, Volume 84, Issue 1 


\section{Одеська національна академія харчових технологій ТЕОРЕТИЧНІ ТА ЕКСПЕРИМЕНТАЛЬНІ ДОСЛІДЖЕННЯ ГІДРАВЛІЧНИХ, ТЕПЛОВИХ ТА МАСООБМІННИХ ПРОЦЕСІВ}

Calculations of thermodynamic parameters for different variants of phosphate interaction reactions with zeolite matrix were given. The most probable scheme of interaction according to the values of isobaric-isothermal potential is established. The thermodynamic parameters of these reactions were calculated. It was found that the chemisorption of phosphate and the formation of poly phosphate in the pores of the sorbent was a spontaneous reaction. For this reaction at temperature $t=298^{\circ} \mathrm{K}$ the isobaric-isothermal potential was $\Delta G=-1202.91, \mathrm{~kJ} / \mathrm{mol}$, entropy change $\Delta S 298=0.397 \mathrm{~kJ} /(\mathrm{mol} \mathrm{K})$, enthalpy change $\Delta H 298=-1084.6 \mathrm{~kJ} / \mathrm{mol}$.

Key words: wastewater, phosphates, zeolite, thermodynamics, thermogravimetry

Аналіз проблематики. У багатьох країнах евтрофікація є основною проблемою забруднення вод озер, водосховищ, океанів тощо [1]. 3 метою вирішення проблем евтрофікації, спричинених традиційними вторинними біологічними стоками, та реалізації повторного використання стічних вод, що зменшує скид стічних вод і покращує стан гірських порід води, в багатьох країнах проводяться дослідження щодо очищення стічних вод від біогенних елементів. Вважається, що сполуки фосфору є основною причиною евтрофікації та неконтрольованого росту синьо-зелених водоростей [2,3]. Основні методи видалення сполук фосфору включають осадження, кристалізацію, біологічне видалення та адсорбцію та іонний обмін [4,5]. 3 огляду на те, що в Україні $є$ значні поклади природних сорбентів, все ж залишається актуальною проблема синтезу сорбентів, які мають строгу відповідність щодо адсорбції певної речовини. Актуальним залишається дослідження теоретико- практичних аспектів застосування природних сорбентів. У першу чергу це встановлення їхньої сорбційної здатності та можливості збільшення їх спорідненості до адсорбата, а також збільшення їх сорбційної ємності через їх модифікацію [6]. Вимагають дослідження рівноважних залежностей процеси адсорбції неорганічних та органічних речовин, катіонного та аніонного складу, одночасної сорбції кількох речовин, оскільки більшість технологічних рідин, а також промислових стоків $є$ багатокомпонентними. Розглянуті у роботі процеси відносяться до масообмінних процесів з твердою фазою. Технологія адсорбції та іонного обміну є більш ефективним способом видалення фосфатів завдяки його перевагам, зокрема, за рахунок компактності очисного обладнання, простому процесу та високій ефективності [7]. Наступним аспектом проблеми вилучення фосфатів зі стічних вод $є$ пошук нових ефективних адсорбціних та іонообмінних матеріалів [8]. Природні цеоліти це алюмосилікати, що містять у своїй структурі ряд каналів, мають велику поверхню коефіцієнта адсорбції порівняно з іншими мінеральними матеріалами. В останні роки дослідники зосереджувались на сорбентах на основі цеолітів. Природні цеоліти є доволі доступними катіонообмінними матеріалами, що застосовуються для очищення води та стічних вод, як каталізатори, тощо. Але встановлено, що цеоліти мають також здатність до адсорбції аніонів $[8,9]$. Тому важливо з'ясувати механізми адсорбції аніонів з метою оптимізації процесів адсорбції з одно та багатокомпонентних розчинів.

Мета роботи - полягала у встановленні термодинамічних, статичних, кінетичних та динамічних закономірностей процесу сорбції фосфатів природними цеолітами.

Аналіз останніх досліджень і публікацій. В попередніх публікаціях було представлено результати експериментальних досліджень щодо адсорбції фосфатів природним цеолітом Сокирницького родовища. Встановлено, що процес адсорбції фосфатів проходить у зовнішньо дифузійній області. Встановлено, що процес адсорбції має ендотермічний характер [8]. Нами було досліджено, що поглинання фосфатів проходить за механізмом хемосорбції. Адсорбційна здатність цеоліту щодо фосфатів пояснюється здатністю утворювати нерозчинні сполуки з іонами кальцію та магнію, які є обмінними катіонами цеоліту. Ці іони виділяються у розчин під час іонообмінної адсорбції фосфатів цеолітом за схемою:

$$
\begin{aligned}
& \mathrm{CL}\left(\mathrm{Na}^{+}\right)_{n}+n \mathrm{Me}^{2+} \rightarrow \mathrm{CL}\left(\mathrm{Me}^{2+}\right)^{+}{ }_{n}+\left(\mathrm{Na}^{+}\right) \\
& \mathrm{CL}\left(\mathrm{Me}^{2+}\right)^{+}{ }_{n}+{ }_{n} \mathrm{H}_{2} \mathrm{PO}_{4}^{-} \rightarrow \mathrm{CL}\left(\mathrm{MeH}_{2} \mathrm{PO}_{4}\right)_{n}
\end{aligned}
$$

Отже, утворення нерозчинних солей фосфатної кислоти забезпечує ефективне виділення фосфат іону. Проблемою вилучення фосфатів сорбційним методом займається багато дослідників. Результати досліджень стосуються синтезу та модифікації сорбційних матеріалів для забезпечення максимальної спорідненості сорбента до фосфатів. обробленому гідроксидом кальцію для видалення фосфату в потоках фосфору 3 низькою концентрацією. 3 цією метою застосовують цеоліти, модифіковані гідроксидом кальцію $\left(\mathrm{Ca}(\mathrm{OH})_{2}\right)$. Подібний досліджували на предмет ефективності видалення фосфатів із стічних вод з очисних споруд Хамірпур, Хімачал-Прадеш, Індія. Згідно результатів досліджень, процес адсорбції фосфатів не залежав від рН, що забезпечує використання цього сорбенту разом із звичайними процесами водоочищення. [10]. Часто застосовують гідроксиаратит, кальцити, доломіти. Щодо механізмів адсорбції, то більшість авторів підтримує думку, що має місце механізм хемосорбції з утворенням нерозчинних фосфатів. Попередні наші дослі- 
дження показали, що адсорбція розчинів фосфатів 3 концентрацією понад 200 мг/дм супроводжується аномальним збільшенням сорбційної ємності цеоліту, що характерно для полімолекулярної адсорбції [8].

Експериментальні дослідження. Дослідження адсорбційної ємності цеоліту щодо фосфатів 3 розчинів ортофосфорної кислоти фотометричним методом згідно відомої методики [6]. Термогравіметричний наліз зразків цеоліту було виконано за допомогою термоаналізатора марки Mettler TGA/SDTA 851е. Щодо статики адсорбції аніонів, то тут має місце багатошарова адсорбція, яка, можливо, в деяких умовах може розглядатися як полімолекулярна адсорбція. Зокрема слід відмітити, що ізотерма адсорбції фосфатів більш підлягає під ізотерму адсорбції Ленгмюра, а виділена окрема ізотерма адсорбції фосфатів була інтерпретована ізотермою БЕТ. Ізотерма БЕТ є фактично розширеною версією ізотерми Ленгмюра і справедлива для систем, у яких має місце полімолекулярна адсорбція, або поліконденсація. Графічна інтерпретація експериментальних даних щодо адсорбції ортофосфорної кислоти природним цеолітом ізотермою БЕТ для площі початкових концентрацій до 375 мг / дм³ представлена на рис. 1. Параметри рівняння БЕТ для процесу адсорбції фосфату цеолітом наступні: $1 /\left(\mathrm{a}_{\mathrm{m}} \mathrm{K}\right)=0.0196 ;\left(\mathrm{K}^{-1}\right) /\left(\mathrm{a}_{\mathrm{m}} \mathrm{K}\right)=0.3304 ; \mathrm{K}=0.99352416 ;$ максимальне значення адсорбційної здатності на фосфатах у полімолекулярному шарі $\mathrm{a}_{\mathrm{m}}=51,35296$.

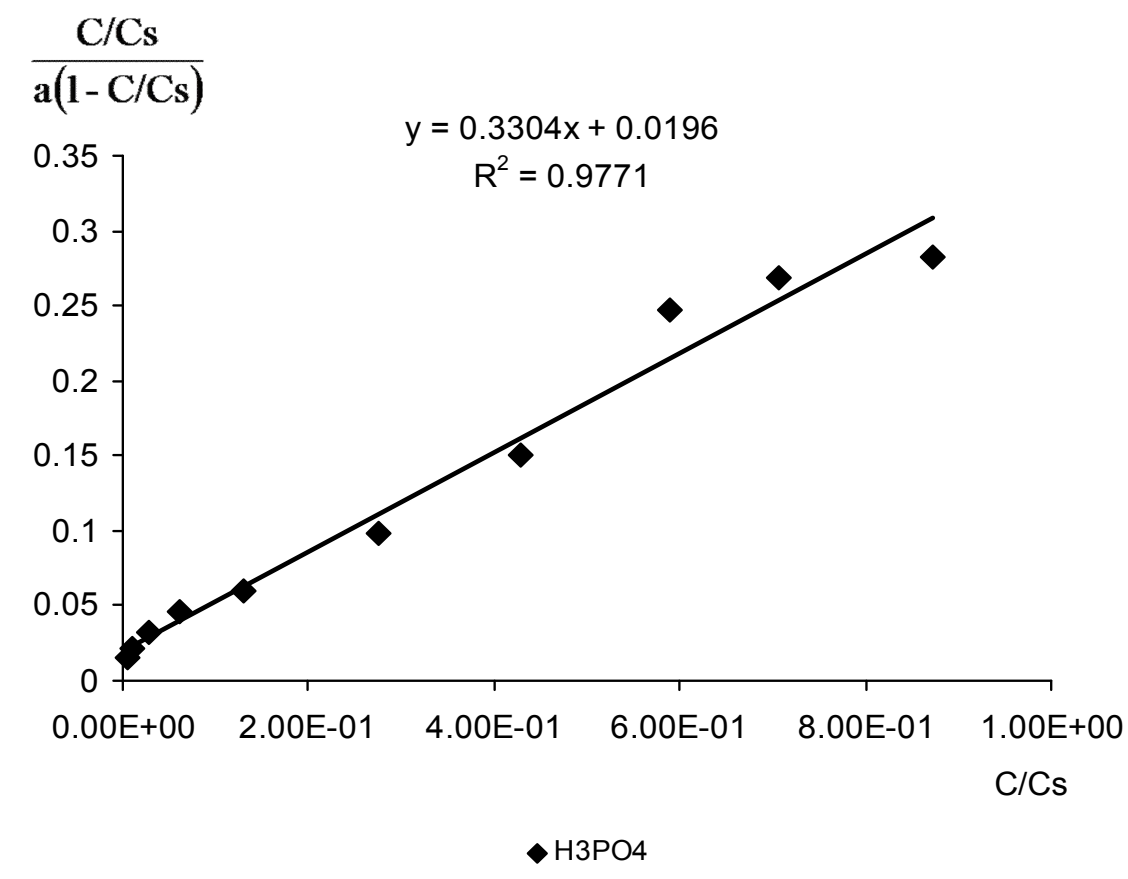

\section{Рис. 1 - Лінеаризована ізотерма БЕТ для адсорбції ортофосфорної кислоти природним цеолітом}

3 рис. 1 випливає, що ізотерма адсорбції ортофосфорної кислоти підпорядковується теорії БЕТ $\left(\mathrm{R}^{2}=0.9771\right)$.

Результати диференційно-термогравіметричного аналізу (ДТА), представлені на рис. 2 і 3 було визначено вплив температури на цеоліту до та після адсорбції фосфатів. Нами встановлено температурні інтервали дегідратації та структурних змін досліджуваних матеріалів. Згідно з даними термогравіметричних диференційної (ДТА) та похідної (ТГП) кривих, в інтервалі температур 20 - 400 $\mathrm{C}$ спостерігається основна втрата маси досліджуваних матеріалів. Видалення фізично адсорбованої вологи з цеоліту відповідає втраті маси в температурному інтервалі 20 - $180^{\circ} \mathrm{C}$. Видалення лігандованої - координаційно зв'язаної вологи у кристалічній гратці цеолітів відбувається в температурному інтервалі $180-400^{\circ} \mathrm{C}$. Зразок цеоліту після адсорбції фосфатів в обдасті $110-130^{\circ} \mathrm{C}$ не проявляв екзоефекту, характерного для природного цеоліту. В інтервалі температур $400-525^{\circ} \mathrm{C}$ в обох зразках спостерігали процес дегідроксилювання поверхні за рахунок відщеплення ОН-груп від $\mathrm{Ca}(\mathrm{OH})_{2}$. В температурному інтервалі $525-780{ }^{\circ} \mathrm{C}$ відбувається розклад $\mathrm{CaCO}_{3}$, а за температур $780-1000^{\circ} \mathrm{C}$ відбувається активне виділення $\mathrm{CO}_{2} .3$ рис. 3 видно, що зразок цеоліту після адсорбції фосфатів мав дещо меншу втрату маси. 


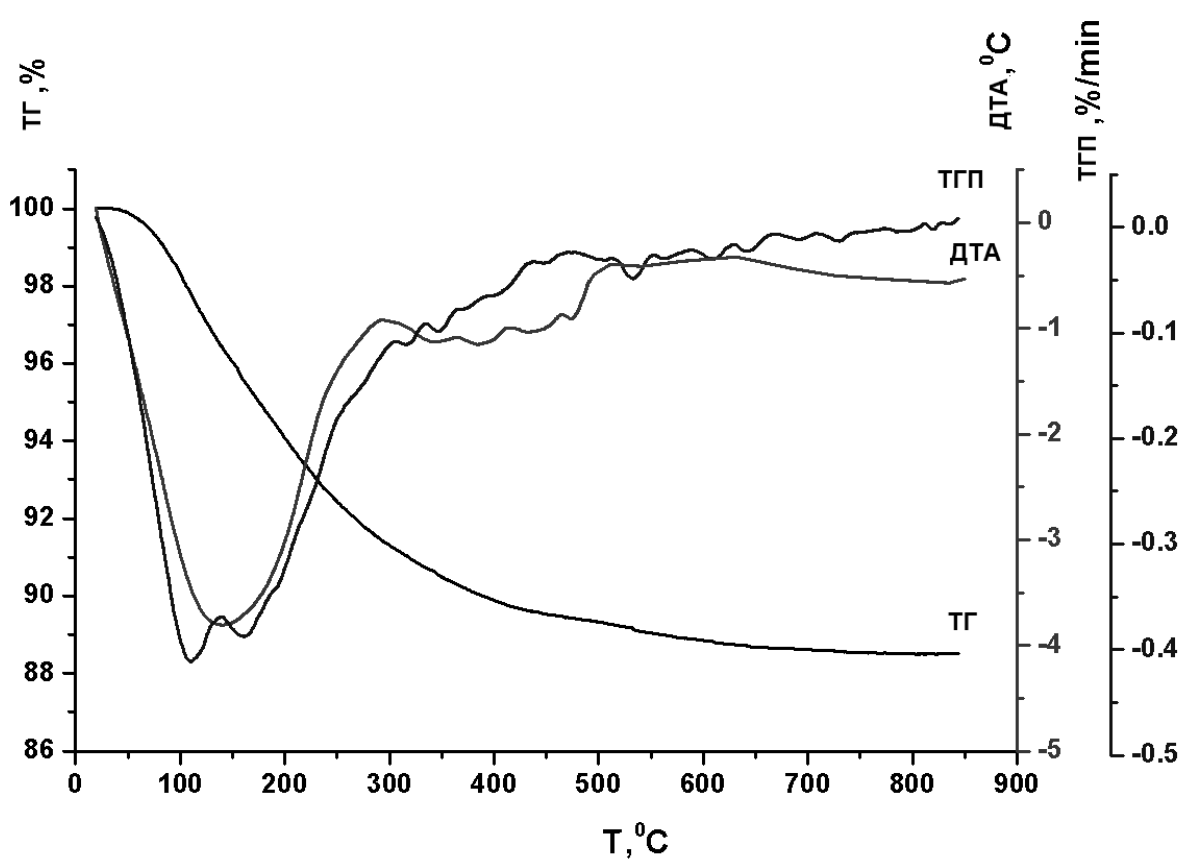

Рис. 2 - Термограма природного цеоліту

Результати термогравіметричного аналізу показали на області фазових переходів в діапазоні температур $600-700^{\circ} \mathrm{C}$ (відповідає температурі плавлення Тпл $=622^{\circ} \mathrm{C}$ та $380{ }^{\circ} \mathrm{C}$, що входить у температурний діапазон розкладу полімеру. Тому можемо стверджувати, що на поверхні цеоліту можуть утворюватися поліфосфати, зокрема натрію трифосфат.

Тому нашим завданням було встановити термодинамічну ймовірність полімолекулярної адсорбції ортофосфорної кислоти природним цеолітом. Результати термогравіметричного аналізу (рис. 2-3) показали області фазових переходів в діапазоні температур $600-700^{\circ} \mathrm{C}$ (відповідає температурі плавлення Тпл=622 ${ }^{\circ} \mathrm{C}$ та $380^{\circ} \mathrm{C}$, що входить у температурний діапазон розкладу полімеру.

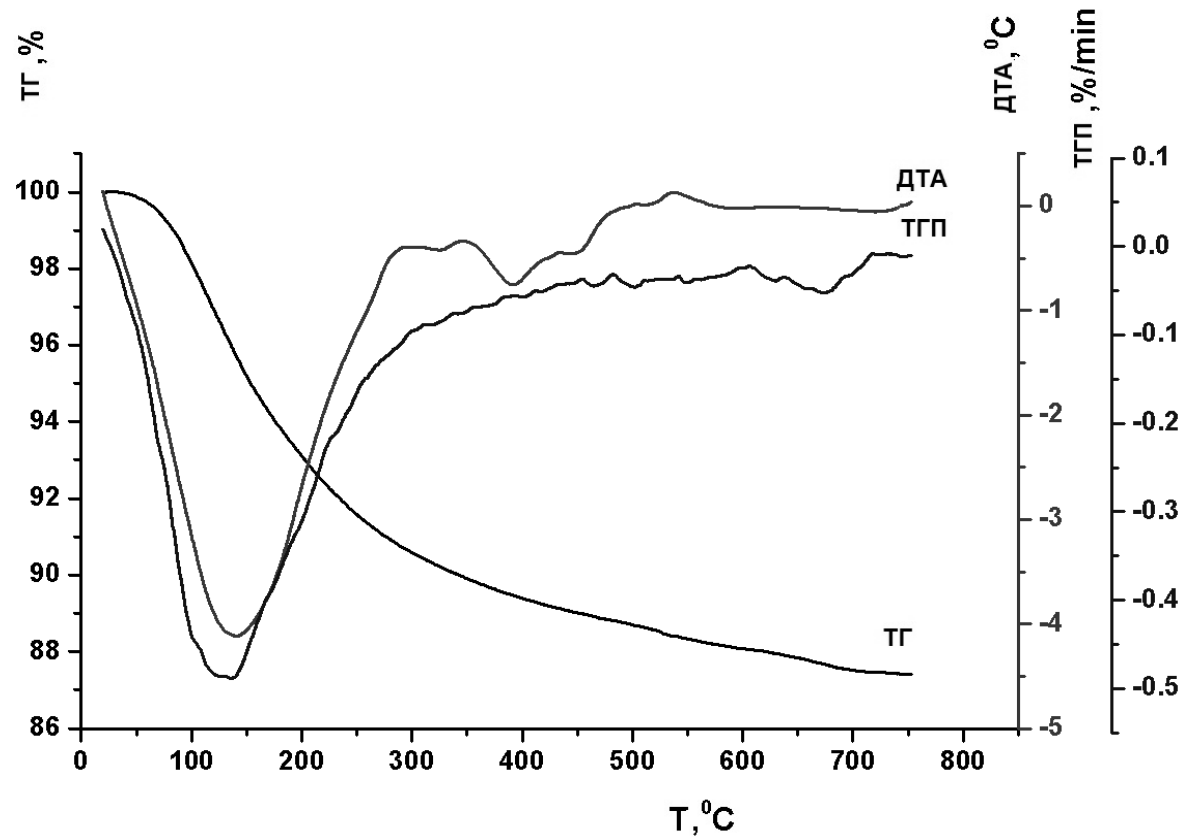

Рис. 3 - Термограма цеоліту після адсорбції $10 \%$ розчину $\mathrm{H}_{3} \mathrm{PO}_{4}$ 
Згідно даних термогравіметричного аналізу, найбільш імовірним механізмом утворення полі фосфату буде рівняння (3). Для спрощення опису механізму приймаємо, що в результаті іонного обміну на цеоліті у розчин потрапляє обмінний катіон цеоліту згідно (1), що можна представити як гідроксид лужного, або лужноземельного металу:

$$
3 \mathrm{H}_{3} \mathrm{PO}_{4}+3 \mathrm{NaOH} \rightarrow \mathrm{Na}_{5} \mathrm{P}_{3} \mathrm{O}_{10}+7 \mathrm{H}_{2} \mathrm{O}
$$

Тепловий ефект процесу розраховували згідно закону Гесса:

$$
\Delta G_{0}^{298}=\Delta \mathrm{H}_{0}^{298}-T \Delta S_{0}^{298} \frac{k J}{m o l}
$$

де $\Delta \mathrm{G}_{0}^{298}$-, зміна ізобарно-ізотермічного потенціалу кДж / моль; $\Delta \mathrm{S}_{0}{ }^{298}$ - зміна ентропії системи, кДж / (моль $\cdot К) ; ~ \Delta \mathrm{H}_{0}^{298}$ - зміна ентальпії, кДж / (моль); Т- абсолютна температура системи, К.

Стан рівноваги досліджуваної термодинамічної системи залежить від співвідношення зміни ентропії та ентальпії. За температури $\mathrm{T}=\mathrm{dH} / \mathrm{dS}$ термодинамічна система буде перебувати у стані рівноваги [7].

Зміну ентропії ми розрахували згідно з таким рівнянням:

$$
\Delta \mathrm{S}_{0}^{298}=\sum \Delta \mathrm{S}_{0}^{298}{ }_{\text {п.р }}-\sum \Delta \mathrm{S}_{0}^{298} \text { вих }, \frac{k J}{\mathrm{~mol} \cdot \mathrm{K}}
$$

Тепловий ефект процесу розраховували згідно закону Гесса:

$$
\Delta H_{0}^{298}=\sum \Delta H_{0}^{298}-\sum \Delta H_{0}^{298}, \frac{k J}{m o l}
$$

За стандартних умов ( $\mathrm{T}=298$ К) зміна енергії Гіббса також залежить від співвідношення зміни ентальпії та ентропії [2]. Розрахунок термодинамічних параметрів за цими рівняннями наведено в таблиці 1.

Термодинамічні параметри полімолекулярної адсорбції фосфатів

\begin{tabular}{|c|c|c|c|c|}
\hline $\begin{array}{c}\text { Тип речовини, } \\
\text { формула }\end{array}$ & $\begin{array}{c}\Delta \mathrm{H}^{\circ}{ }_{298}, \mathrm{M} \text { дж / } \\
\text { моль }\end{array}$ & $\begin{array}{c}\Delta \mathrm{S}^{\circ}{ }_{298}, \mathrm{~K} \text { Дж / } \\
\text { моль } \mathrm{K}\end{array}$ & $\begin{array}{c}\Delta \mathrm{G}, \mathrm{M} \text { Дж/моль } \\
\mathrm{t}=298{ }^{\circ} \mathrm{K}\end{array}$ & $\begin{array}{c}\text { Рівноважна } \\
\text { температура, }{ }^{\circ} \mathrm{K} \\
\mathrm{t}_{\mathrm{eq}}=\mathrm{dH} / \mathrm{dS}\end{array}$ \\
\hline Реагент $\mathrm{NaOH}$ & -0.496 & 0.048 & -0.415 & - \\
\hline Реагент $\mathrm{H}_{3} \mathrm{PO}_{4}$ & -1.279 & 0.11 & -1.279 & - \\
\hline $\begin{array}{c}\text { Реактант } \\
\mathrm{Na}_{5} \mathrm{P}_{3} \mathrm{O}_{10}\end{array}$ & -4.409 & 0.381 & -4.100 & - \\
\hline Реактант $\mathrm{H}_{2} \mathrm{O}$ & -0.286 & 0.07 & -0.237 & - \\
\hline $\begin{array}{c}\text { Значення термоди- } \\
\text { намічних параметрів }\end{array}$ & -1.085 & 0.397 & -1.201 & -2732 \\
\hline
\end{tabular}

Для реакції (1)за температури $\mathrm{t}=298{ }^{\circ} \mathrm{K}$ ізобарно-ізотермічний потенціал становив $\Delta \mathrm{G}=-1202.91$, кДж / моль, зміна ентропії $\Delta \mathrm{S}_{298}^{\circ}=0.397$ кДж / (моль К), зміна ентальпії $\Delta \mathrm{H}^{\circ}{ }_{298}=-1084.6$ кДж / моль,

Ізобарно-ізотермічний потенціал, тобто зміна стандартної енергії Гіббса досліджуваної термодинамічної системи $\Delta \mathrm{G}<0$. Отже, хімічна реакція (1) в порах цеоліту може відбуватися навіть за нормальних умов. Збільшення температури термодинамічної системи буде збільшувати швидкість прямої реакції. Таким чином, можна стверджувати про утворення поліфосфатів в порах цеолітів під час адсорбції ортофосфорної кислоти. 
Висновки. Аналіз результатів експериментальних досліджень фосфатів природним цеолітом показав, що в процесі адсорбції ортофосфорної кислоти можуть проходити за механізмом полімолекулярної адсорбції. Проведено термогравіметричні дослідження природного та відпрацьованого цеоліту, встановлено області фазових переходів, що вказують на плавлення та розклад полі фосфатів. Встановлено, що в процесі адсорбції фосфатів цеолітом з розчинів понад 200 мг/дм³ має місце спонтанний процес полі молекулярної адсорбції.

\section{References}

1. Uygur, V., Celik, C. S., Sukusu, E., Mujdeci, M. (2017). The effect of particle size on phosphorus adsorption kinetic and desorption by turkish natural zeolites. Fresenius Environmental Bulletin, 26(10), 6253-6260.

2. Kawasaki, N., Ogata, F., Takahashi, K. et al. (2008). Relationship between anion adsorption and physicochemical properties of aluminum oxide. Journal of health science, 54(3), 324-329, doi: $10.1248 /$ jhs. 54.324

3. Khan, M. N., Sarwar, A. (2007). Determination of point zero charge of natural and treated adsorbents. Surf. Rev. Lett., 14, 461-469.

4. Awasthi, M., Kumar, S. (2020). Analysis of Phosphate Removal using Ca (OH) 2 Modified Zeolite Based Adsorbents, IWRA (India) Journal (Half Yearly Technical Journal of Indian Geographical Committee of IWRA), 9(1), 37-43.

5. Shi, W., Fu, Y., Jiang, W., et al. (2019). Enhanced phosphate removal by zeolite loaded with Mg-Al-La ternary (hydr) oxides from aqueous solutions: Performance and mechanism. Chemical Engineering Journal, 357, 33 44.

6. Girish, S. R. (2017). Various isotherm models for multicomponent adsorption: a review. International Journal of Civil Engineering and Technology (IJCIET), 8(10), 80-86.

7. Sabadash, V., Gumnitsky, J., Lyuta, O., Pochapska, I. (2018). Thermodynamics of $\left(\mathrm{NH}_{4}^{+}\right)$cation adsorption under static conditions. Chemistry \& Chemical Technology, 12(2), 143-146.

8. Sabadash, V., Hyvlyud, A., Gumnitsky, Ya. (2016). Mechanism of phosphates sorption by zeolites depending on degree of their substitution for potassium ions. Chemistry \& Chemical Technology. 10(2), 235-240.

9. He, Y., Liu, L., He, L., Cui, X. (2016). Characterization of chemosynthetic $\mathrm{H}_{3} \mathrm{PO}_{4}-\mathrm{Al}_{2} \mathrm{O}_{3}-2 \mathrm{SiO}_{2}$ geopolymers. Ceramics International, 42(9), 10908-10912.

10. Teow, Y. H., Mohammad, A. W. (2019). New generation nanomaterials for water desalination: a review. Desalination, 451, 2-17.

Отримано в редакцію 17.06.2020

Прийнято до друку 22.10.2020
Received 17.06.2020

Approved 22.10.2020 